\title{
Penentuan Zona Pengembangan Bangunan Tinggi Di Koridor Jalan Raya Jemursari
}

\author{
Dhimas Yogi Nurrohman dan Ardy Maulidy Navastara \\ Perencanaan Wilayah dan Kota, Fakultas Arsitektur, Desain dan Perencanaan \\ Institut Teknologi Sepuluh Nopember (ITS) \\ e-mail: ardy.navastara@urplan.its.ac.id
}

\begin{abstract}
Abstrak-Terkait dengan padatnya pembangunan fisik yang sudah menghiasi kota Surabaya, dalam penelitian ini khususnya wilayah Surabaya Selatan pada Koridor Jalan Raya Jemursari, sedangkan pengajuan pembangunan bangunan tinggi dari investor terus berdatangan, maka dari itu diperlukan suatu bentuk pembatasan agar pembangunan bangunan tinggi lebih terkontrol karena pada dasarnya bangunan tinggi tidak dapat dibangun disembarang tempat. Oleh karena itu perlu diteliti mengenai zona yang potensial bagi pembangunan bangunan tinggi.
\end{abstract}

Kata Kunci-Bangunan Tinggi, Lokasi Potensial, Zona.

\section{PENDAHULUAN}

L AHAN mempunyai peranan penting dalam kehidupan manusia, tumbuhan dan makhluk lainnya. Manusia selalu berusaha memiliki dan menguasai lahan yang ikut menentukan status sosialnya. Lahan dapat diartikan sebagai land settlemen yaitu suatu tempat atau daerah dimana penduduk berkumpul dan hidup bersama, dimana mereka dapat menggunakan lingkungan setempat untuk mempertahankan, melangsungkan dan mengembangkan hidupnya. Menurut Arsyad (1989:207) mengatakan bahwa lahan diartikan sebagai lingkungan fisik yang terdiri atas iklim, relief, tanah, air dan vegetasi serta benda yang ada di atasnya sepanjang ada pengaruhnya terhadap penggunaan lahan. Penggunaan lahan merupakan upaya yang dilakukan manusia dalam pemanfaatan lahan sehingga produktivitas lahan tetap tinggi secara berkelanjutan. Pelaksanaan penataan ruang adalah upaya pencapaian tujuan penataan ruang melalui pelaksanaan perencanaan tata ruang, pemanfaatan ruang, dan pengendalian pemanfaatan ruang. Sejalan dengan hal itu, maka pengaturan penggunaan lahan pada kawasan terbangun dan telah memiliki fungsi kegiatan tertentu adalah bentuk pengendalian pemanfaatan ruang. Kota Surabaya sebagai kota terbesar kedua di Indonesia semakin diperhitungkan. Ibu kota Jawa Timur ini telah bertransformasi demikian signifikan sehingga menjadi incaran perusahaan-perusahaan nasional dan juga multinasional merealisasikan ekspansi bisnisnya. Hal tersebut terindikasi dari menjamurnya pengembangan pusat belanja (ritel), perkantoran, apartemen, dan perhotelan. Pesatnya pembangunan gedung tinggi di Kota Surabaya dapat terlihat salah satunya pada koridor Jalan Raya Jemursari. Terkait tata guna lahan dan pemanfaatan lahan kegiatan perdagangan dan jasa, terdapat permasalahan pembangunan yang tidak sesuai dengan aturan tata guna lahan dan pemanfaatan lahan. Kondisi yang terlihat di koridor Jalan Raya Jemursari telah banyak terdapat bangunan tinggi seperti berupa perhotelan kelas berbintang serta bangunan gedung tinggi lainnya, dalam hal ini tentu juga harus memperhatikan perencanaan daerah yang tercantum dalam RDTRK Kota Surabaya mengenai arahan intensitas bangunan maupun lahan.

Surabaya, being a metropolitan city, has a built-area covering up to two-thirds of its total area. Residential development is one of the motors for development, and it will continue to expand. The 2013 Surabaya Spatial Plan (RTRW 2013) indicates that physical growth of the urban environment is concentrated within the city center, running along the north-south axis. Currently dominated by real estate and commercial facilities development, physical development shifts towards the eastern and western parts of the city [1].

\section{METODE PENELITIAN}

\section{A. Jenis dan Pendekatan Penelitian}

Pendekatan yang digunakan dalam arahan zona pengembangan bangunan tinggi terhadap kesesuaian lahan adalah pendekatan kulitatif dan kuantitatif. Pelaksanaan penelitian ini dilakukan dengan melakukan survei primer yang meliputi wawancara dan kuisioner, dan survei sekunder yang meliputi instansi dan literatur.

\section{B. Variabel Penelitian}

Penentuan variabel penelitian ini berdasarkan pada kriteria arahan zona pengembangan bangunan tinggi di koridor Jalan Raya Jemursari, dalam hal tersebut merupakan hasil sintesis dari kajian pustaka. Faktor dan variabel dalam penelitian arahan zona pengembangan bangunan tinggi di tampilkan pada tabel berikut:

Tabel 1.

Variabel Penentuan Zona Pengembangan

\begin{tabular}{|c|l|l|l|}
\hline No & \multicolumn{1}{|c|}{ Kriteria } & \multicolumn{1}{|c|}{ Indikator } & \multicolumn{1}{c|}{ Variabel } \\
\hline 1 & $\begin{array}{l}\text { Ketersediaan } \\
\text { lahan }\end{array}$ & $\begin{array}{l}\text { Keberadaan lahan } \\
\text { potensial }\end{array}$ & $\begin{array}{l}\text { ・ Luas kavling } \\
\text { - Nilai lahan } \\
\text { - Ketinggian terkait } \\
\text { KDB/KLB }\end{array}$ \\
& & & \\
\hline 2 & Aksesibilitas & $\begin{array}{l}\text { Kompleksitas } \\
\text { kegiatan }\end{array}$ & $\bullet$ Fungsi jalan \\
\hline
\end{tabular}

\section{Metode Pengumpulan Data}

Metode perolehan data untuk penelitian ini dilakukan 
dengan survei primer dan survei sekunder. Survei ini dilakukan untuk mencari data yang bersifat kuantitatif dan kualitatif Metode Analisis.

Teknik analisa yang digunakan dalam studi ini adalah teknik analisis kualitatif dan kuantitatif serta analisis peta menggunakan teknik Overlay pada ArcGis, dan kesimpulan dari hasil pengamatan akan menjadi hasil analisis. Hasil analisa yang telah dilakukan, akan di validasi. Pada proses validasi penelitian tersebut, peneliti membutuhkan penilaian yang dikonsultasikan pada ahli dibidangnya (expert judgement).

Tabel 2.

Metode Analisis

\begin{tabular}{|c|c|c|c|}
\hline Sasaran & Data Input & $\begin{array}{c}\text { Teknik } \\
\text { Analisis }\end{array}$ & Output \\
\hline \multirow{6}{*}{$\begin{array}{l}\text { Identifikasi } \\
\text { faktor-faktor } \\
\text { penentuan lokasi } \\
\text { potensial } \\
\text { pembangunan } \\
\text { bangunan tinggi di } \\
\text { koridor Jalan Raya } \\
\text { Jemursari. }\end{array}$} & Luas kavling & \multirow[t]{6}{*}{$\begin{array}{l}\text { Analisis } \\
\text { Delphi }\end{array}$} & \multirow{6}{*}{$\begin{array}{l}\text { Faktor-faktor yang } \\
\text { menjadi } \\
\text { pertimbangan } \\
\text { dalam penentuan } \\
\text { lokasi potensial } \\
\text { pembangunan } \\
\text { bangunan tinggi. }\end{array}$} \\
\hline & Nilai lahan & & \\
\hline & $\begin{array}{l}\text { Ketinggian } \\
\text { terkait KLB }\end{array}$ & & \\
\hline & $\begin{array}{l}\text { Tarikan dan } \\
\text { bangkitan lalu } \\
\text { lintas }\end{array}$ & & \\
\hline & Fungsi jalan & & \\
\hline & $\begin{array}{l}\text { Ketinggian } \\
\text { optimal yang } \\
\text { dapat } \\
\text { dibangun }\end{array}$ & & \\
\hline $\begin{array}{l}\text { Penentuan zona } \\
\text { pengembangan } \\
\text { kawasan bangunan } \\
\text { tinggi di wilayah } \\
\text { penelitian. }\end{array}$ & $\begin{array}{l}\text { Hasil dari } \\
\text { sasaran I }\end{array}$ & $\begin{array}{l}\text { Teknik } \\
\text { Overlay (GIS) }\end{array}$ & $\begin{array}{l}\text { Peta zona kawasan } \\
\text { bangunan tinggi. }\end{array}$ \\
\hline $\begin{array}{l}\text { Arahan } \\
\text { pengembangan } \\
\text { kawasan bangunan } \\
\text { tinggi. }\end{array}$ & $\begin{array}{l}\text { Hasil dari } \\
\text { sasaran I dan } \\
\text { II }\end{array}$ & $\begin{array}{l}\text { Analisis } \\
\text { Kualititatif } \\
\text { (Expert } \\
\text { Judgement) }\end{array}$ & $\begin{array}{l}\text { Arahan zona } \\
\text { pengembangan } \\
\text { bangunan tinggi di } \\
\text { koridor jalan Raya } \\
\text { Jemursari. }\end{array}$ \\
\hline
\end{tabular}

\section{HASIL DAN DISKUSI}

Untuk proses analisis pada penentuan zona pengembangan bangunan tinggi di koridor jalan Raya Jemursari menggunakan alat analisis teknik Overlay.

Setelah didapatkan faktor dalam penentuan lokasi potensial di kawasan studi, yaitu luas kavling, nilai lahan, ketinggian terkait Koefisien Lantai Bangunan/KLB, tarikan dan bangkitan, serta fungsi jalan. Maka faktor tersebut di atas dijadikan peta dasar dalam teknik Overlay pada ArcGis sehingga didapat zona kawasan.

Tabel 3.

Penentuan Parameter Tingkat Potensi Tiap Faktor

\begin{tabular}{l|l|l|c} 
Variabel & Definisi Operasionsl & Parameter & Nilai \\
\hline
\end{tabular}

\begin{tabular}{|c|c|c|c|}
\hline \multirow{3}{*}{ Luas Lahan } & \multirow{3}{*}{$\begin{array}{l}\text { Semakin lahan yang } \\
\text { tersedia luas, maka } \\
\text { masuk dalam kategori } \\
\text { potensial }\end{array}$} & $0-3 \mathrm{Ha}$ & 1 \\
\hline & & $3-25 \mathrm{Ha}$ & 2 \\
\hline & & $>25 \mathrm{Ha}$ & 3 \\
\hline \multirow{3}{*}{ Harga Lahan } & \multirow{3}{*}{$\begin{array}{l}\text { Semakin tinggi harga } \\
\text { lahan potensi untuk } \\
\text { pembangunan bangunan } \\
\text { tinggi rendah }\end{array}$} & $0-4.000 .000$ & 3 \\
\hline & & $\begin{array}{c}4.000 .000- \\
8.000 .000\end{array}$ & 2 \\
\hline & & $>8.000 .000$ & 1 \\
\hline \multirow{3}{*}{$\begin{array}{l}\text { Ketinggian terkait } \\
\text { KLB }\end{array}$} & \multirow{3}{*}{$\begin{array}{l}\text { Semakin rendah kondisi } \\
\text { eksisting KLB maka } \\
\text { semakin untuk dikuasai } \\
\text { investor menjadi } \\
\text { bangunan tinggi }\end{array}$} & $0-3$ lantai & 3 \\
\hline & & $4-6$ lantai & 2 \\
\hline & & $7-9$ lantai & 1 \\
\hline Fungsi Jalan & $\begin{array}{l}\text { Kesesuaian fungsi jalan } \\
\text { eksisting terhadap } \\
\text { bangunan tinggi }\end{array}$ & Arteri Sekunder & - \\
\hline
\end{tabular}

Berikut ini merupakan data hasil analisis tiap faktor.

Tabel 4.

Parameter Skala Luas Lahan

\begin{tabular}{|c|c|c|}
\hline Kelas Skala Luas & Nilai & Luas (Ha) \\
\hline $0-3 \mathrm{Ha}$ & 1 & 49,63 \\
\hline $3-25 \mathrm{Ha}$ & 2 & 7,78 \\
\hline$>25 \mathrm{Ha}$ & 3 & 0 \\
\hline \multicolumn{2}{|c|}{ Total } & 57,41 \\
\hline
\end{tabular}

Berdasarkan hasil identifika luas lahan ditentukan parameter skala luas pada tabel 4 Luas lahan merupakan salah satu dari penentuan lokasi potensial kawasan bangunan tinggi. Pada tabel 4 dapat dijelaskan bahawa kelas skala luas $0-3$ Hektar masuk dalam penilaian angka 1 yang berarti tingkat potensinya rendah. Kemudian kelas skala luas 3 - 25 Hektar masuk dalam penilaian angka 2 yaitu tingkat potensinya sedang. Sedang pada kelas skala lebih dari 25 Hektar tidak terdapat pada kondis eksisting luas luas lahan di wilayah studi.

Tabel 5.

Parameter Skala Haraga Lahan

\begin{tabular}{|c|c|c|}
\hline Skala Harga (Rp) & Nilai & Luas (Ha) \\
\hline $0-4.000 .000$ & 3 & 12,90 \\
\hline $4.000 .000-8.000 .000$ & 2 & 21,64 \\
\hline$>8.000 .000$ & 1 & 22,87 \\
\hline Total & 57,41 \\
\hline
\end{tabular}

Selain luas lahan yang merupakan salah satu dari penentu lokasi potensial kawasan bangunan tinggi, terdapat juga nilai lahan. Berdasarkan pada tabel 5 untuk skala harga 0 - 
4.000.000 masuk dalam penilaian angka 3 yang berarti tingkat potensi tinggi. Kemudian pada skala harga 4.000.000 8.000.000 masuk dalam penilaian angka 2 dengan potensi sedang. Sedang skala harga lebih dari 8.000 .000 masuk dalam penilaian angka 1 dengan tingkat potensi rendah.

Tabel 6.

Parameter skala ketinggian lantai terkait KLB

\begin{tabular}{|c|c|c|}
\hline Skala ketinggian (KLB) & Nilai & Luas (Ha) \\
\hline $0-3$ lantai & 3 & 50,74 \\
\hline $4-6$ lantai & 2 & 5,91 \\
\hline$>7$ lantai & 1 & 0,75 \\
\hline \multicolumn{2}{|c|}{ Total } & 57,41 \\
\hline
\end{tabular}

Faktor selanjutnya yang menjadi salah satu faktor penentuan lokasi potensial kawasan bangunan tinggi adalah koefisien lantai bangunan, dimana dari tabel diatas dapat diketahui skala Koefisien Lantai Bangunan (KLB) 0 - 3 lantai masuk dalam penilaian angka 3 dengan potensi tinggi. Kemudian pada skala 4 - 6 lantai dalam penilaian angka 2 dengan kategori tingkat potensi sedang. Sedangkan skala $7-9$ lantai pada penilaian angka 1 dengan tingkat potensi rendah.

\section{A. Faktor Fungsi Jalan}

Menurut Rencana Tata Ruang Wilayah Kota Surabaya yang diatur dalam Peraturan Daerah Nomor 12 Tahun 2014, maka Jalan Raya Jemursari memiliki fungsi jalan sebagai jalan arteri sekunder dengan kelas jalan adalah III/B. Jalan arteri sekunder adalah jalan arteri yang menghubungkan antara kawasan primer dan kawasan sekunder kesatu, antar kawasan sekunder kesatu, atau antara kawasan sekunder kesatu dan antar kedua (Peraturan Pemerintah No.26 Tahun 1985).

Ciri-ciri jalan arteri sekunder, yaitu:

- Didesain berdasarkan kecepatan rencana paling rendah 30 (tiga puluh) $\mathrm{km} / \mathrm{jam}$ dan dengan lebar badan jalan tidak kurang dari 11 (sebelas) meter.

- Mempunyai kapasitas yang lebih besar dari volume lalu lintas rata-rata.

- Lalu lintas cepat tidak boleh terganggu oleh lalu lintas lambat.

- Pengaturan pada persimpangan jalan sebidang.

\section{B. Arahan Zona pengembangan bangunan tinggi di Koridor Jalan Raya Jemursari}

Dari hasil identifikasi faktor-faktor penentuan lokasi potensial kawasan bangunan tinggi yang berupa tabel luas lahan, harga lahan dan ketinggian terkait koefisien lantai bangunan yang dikelompokkan dalam 3 kelas parameter, maka berdasarkan kesamaan karakter kelas-kelas tersebut selanjutnya dapat ditentukan beberapa zona arahan pengembangan kawasan bangunan tinggi di koridor jalan raya Jemursari yang dapat tergambarkan dari peta hasil overlay dari ke 4 faktor tersebut di atas.

Tabel 7.

Zona Pengembangan Bangunan Tinggi

\begin{tabular}{|c|c|c|}
\hline Tingkat Potensi & Skala Penilaian & Luas (Ha) \\
\hline Rendah & $0-3$ & 0 \\
\hline Sedang & $4-6$ & 40,763 \\
\hline Tinggi & $7-9$ & 16,646 \\
\hline \multicolumn{2}{|c|}{ Total } \\
\hline
\end{tabular}

Dari hasil analisis peta yang telah tersedia pada tabel 7 tersebut dapat jelaskan mengenai arahan zona pengembangan bangunan tinggi di kawasan studi, yaitu: terlihat pada peta 1 zona yang terlihat mendominasi pada jalan raya Jemursari masuk dalam kategori zona potensi sedang dengan tertanda blok berwarna hijau. Kemudian untuk pada peta 1 terkait zona dengan tingkat potensi tinggi rata-rata terdapat pada bagian selatan, tetapi juga masih terdapat beberapa zona dengan tingkat potensi kategori tinggi di bagian utara dari koridor jalan Raya Jemursari, lebih terperinci lagi zona tinggi tersebut tertanda dengan blok berwarna merah.

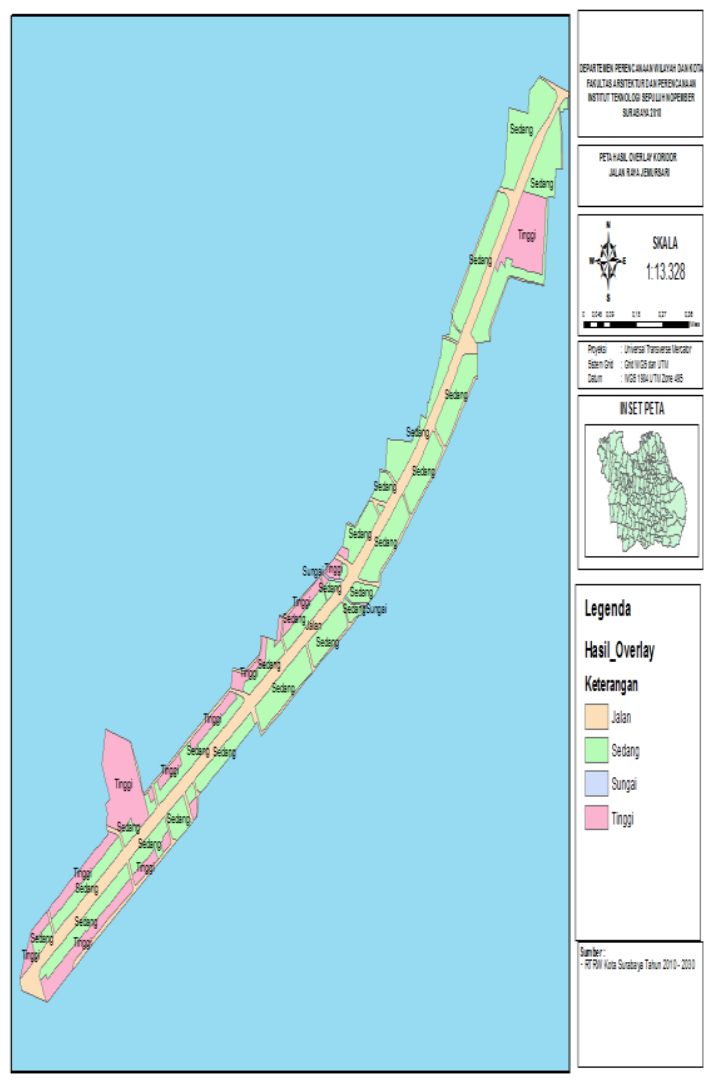

Gambar 1. Peta hasil overlay dari ke 4 faktor

\section{KESIMPULAN}

Dari hasil analisis penentuan zona didapatkan zona di kawasan studi yaitu zona sedang dan zona rendah. Zona sedang diartikan sebangai zona dengan tingkat potensi sedang untuk pengembangan skala sedang, karena ukuran luas kavling rata-rata sedang maka diarahkan untuk bangunan kurang dari 6 lantai dengan luas kavling keseluruhan 40,763 Ha. Kemudian untuk zona tinggi yaitu zona dengan tingkat potenasi pengembangan dalam skala tinggi, karena ukuran kavling cukup luas disertai dengan harga lahan relatif sedang maka tingkat pengembangannya masuk dalam kategori tinggi.

\section{Saran}

Adapun saran yang dapat disampaikan oleh penulis terkait permasalah dalam penulisan skripsi ini adalah sebagai berikut :

1. Saran terkait penulisan penelitian ini juga ditujukan kepada penulis berupa hal-hal yang belum atau tidak tercantumkan dalam proses analisis mengenai arahan zona pengembangan 
bangunan tinggi di koridor jalan Raya Jemursari. Saran atau masukan tersebut dpat berupa ditambhakannya point-pint variabel untuk lebih mendukung dalam alat analisis penetuan zona pengembangan bangunan tinggi.

2. Dalam rangka mendukung arahan zona pengembangan bangunan tinggi di koridor Jalan Raya Jemursari, maka Pemerintah Kota Surabaya perlu memperhatikan penyediaan dan pengaturan sistem utilitas perkotaan pada kawasan komersial.

\section{DAFTAR PUSTAKA}

[1] N. Navastara, Ardy Maulidy. Prananda, "Impact of residential land development towards land price dynamics in Surabaya," 11th IRSA Int., 2012. 